\title{
PHYSICAL EDUCATION FOR LIFELONG FITNESS: STRATEGI PENINGKATAN AKTIVITAS FISIK SISWA SEKOLAH DASAR
}

\author{
Indah Prasetyawati Tri Purnama Sari ${ }^{1}$ \\ ${ }^{1}$ Universitas Negeri Yogyakarta, Indonesia
}

\begin{tabular}{ll}
\hline Keyword & Abstrac \\
\hline physical & Noncommunicable diseases (NCDs) or often referred to as \\
education & noncommunicable diseases in the community are currently one of the \\
Physical activity & highest causes of death in the world. Noncommunicable diseases (NCDs), \\
lifelong & apart from being caused by heredity, are also caused by lifestyle, lack of \\
& rest, and physical activity. The World Health Organization (WHO) \\
Corresponding & recommends physical activity as one of the preventive efforts for \\
Author & noncommunicable diseases (NCDs), and one of them is contained in \\
\hline Indah & physical education in schools. However, this effort has not been fully \\
Prasetyawati & implemented in the community. Therefore, strategies from various parties \\
Tri Purnama & are needed to carry out promotive actions related to increasing the \\
Sari & physical activity of elementary school students. Thus, the paper aims to \\
FIKUNY & discuss physical education for lifelong fitness: strategies to increase \\
Indonesia & physical activity for elementary school students. \\
Email: & Abstrak \\
indah_prasty@ & Noncommunicable diseases (NCDs) atau sering disebut sebagai penyakit \\
uny.ac.id & tidak menular di masyarakat, dewasa ini menjadi salah satu penyebeba \\
& kematian tertinggi di Dunia. Noncommunicable diseases (NCDs) selain \\
& disebabkan oleh keturuanan, juga disebabkan pola hidup, kurangnya \\
& istirahat, dan kurangnya aktifitas fisik. World Health Organizatition \\
& (WHO) merekomendasikan tentang aktifitas fisik sebagai salah satu \\
& usaha preventif noncommunicable diseases (NCDs), dan salah satunya \\
& tertuang pada physical education yang ada di sekolah. Akan tetapi usaha \\
& tersebut belum sepenuhnya berjalan di masyarakat. Oleh karena itu, \\
& dipelukan strategi dari berbagai pihak untuk melakukan usaha promotif \\
& edemikian makation for lifelong fitness: strategi peningkatan aktivitas fisik siswa \\
& sekolah dasar.
\end{tabular}

Kata Kunci: Pendidikan, Jasmani Aktivitas fisik, lifelong

\section{PENDAHULUAN}

Aktifitas fisik yang kurang, sekarang ini menjadi diidentifikasi sebagai faktor penyebab utama kematian dan menduduki peringkat ke empat. Kurangnya aktifitas fisik diberbagai negara akan menyebababkan semakin meningkatnya noncommunicable diseases (NCDs) atau biasa disebut dengan penyakit tidak menular. Aktifitas fisik merupakan salah satu usaha dalam pencegahan meningkatnya noncommunicable diseases. Noncommunicable diseases (NCDs) antara lain penyakit jantung, stroke, diabetes millitus, kanker payudara dan kanker usus besar. Selain itu yang termasuk dalam noncommunicable diseases adalah hipertensi, kegemukan dan obesitas. Penyakitpenyakit tersebut adalah penyebab utama kematian, saat ini. 
NCDs sejauh ini merupakan penyebab utama kematian di seluruh dunia. Pada tahun 2016, data menyatakan bahwa dari 71\% (41 juta) dari 57 juta kematian yang terjadi secara global(World Health Organization, 2016). NCDs yang termasuk dalam daftar penyebab kematian antara lain penyakit yang disebabkan oleh kardiovaskular (17,9 juta kematian, terhitung $44 \%$ dari semua kematian NCD dan $31 \%$ dari semua kematian global); kanker (9 juta kematian, 22\% dari semua kematian NCD dan $16 \%$ dari semua kematian global); penyakit pernapasan kronis (3,8 juta kematian, $9 \%$ dari semua kematian NCD dan 7\% dari semua kematian global); dan diabetes (1,6 juta kematian, $4 \%$ dari semua kematian akibat NCD dan 3\% dari semua kematian global). Persentase tertinggi $(75 \%)$ dari kematian orang dewasa prematur terjadi pada usia lanjut (30-69 tahun) disebabkan oleh $\mathrm{NCD}$, hal tersebut menunjukkan bahwa kematian yang disebabkan oleh NCD tidak hanya pada usia lanjut, dengan faktor resiko bahwa untuk laki-laki (22\%) lebih sedikit tinggi dibandingkan dengan wanita (15\%) (González et al., 2017; World Health Organization, 2016).

Data WHO, menyebutkan bahwa di Indonesia, 73\%, kematian disebabkan oleh noncommunicable diseases . kurangnya aktifitas fisik, sebagai salah satu penyebab salah penyakit NCDs. Kejadian kurang aktifitas fisik penduduk Indonesia yang berusia lebih dari 10 tahun sebanyak 48.3 kurang melakukan aktivitas fisik. Kelompok perempuan yang kurang melakukan aktivitas fisik sebesar 54.4\% lebih tinggi dari laki-laki yang memiliki \%tase $41.4 \%$. selain itu hasil tersebet juga diperkuat bahwa daerah urban memiliki \%tase lebih besar yaitu 57.6\% dibanding daerah rural sebesar 43.3\%. Data hasil Riset Kesehatan Dasar (Badan Penelitian dan Pengembangan Kesehatan Kementerian Kesehatan RI, 2013) menunjukkan bahwa di Indonesia, proporsi penduduk usia lebih dari 10 tahun yang tergolong kurang beraktifitas fisik sebesar 26,1\%. Lebih lanjut, terdapat 22 provinsi yang angkanya melebihi angka tersebut. Lima tertinggi adalah provinsi DKI Jakarta (44,2\%), Papua (38,9\%), Papua Barat $(37,8 \%)$, Sulawesi Tenggara dan Aceh (masing-masing 37,2\%). Daerah Istimewa Yogyakarta, proporsi penduduk yang melakukan aktivitas fisik kurang aktif sebesar 20,8\% (Kemenkes RI, 2018).

Aktifitas fisik yang kurang pada anak-anak salah satunya disebabkan karena adanya sedentary behavior yang dilakukan anak-anak setiap hari. Sebagai contoh kebiasaan duduk dengan durasi yang lama. Kebiasaan duduk terlalu lama sangat buruk untuk kesehatan. hal tersebut berkaitan dengan kesehatan mental yang lebih buruk, risiko kematian yang lebih tinggi akibat penyakit jantung dan penyebab lainnya, risiko lebih tinggi untuk menjadi cacat (Dunstan et al., 2012; Medina et al., 2021; Stamatakis et al., 2019).

Salah satu usaha pencegahan meningkatnya noncommunicable diseases secara global melalui aktivitas fisik. Aktifitas fisik dapat dilaksanakan melalui program sekolah, salah satunya pendidikan jasmani, olahraga, dan kesehatan. Pendidikan jasmani yang ada di sekolah adalah bagian penting dari program pendidikan komprehensif dan menyeluruh untuk siswa, dengan ditunjang sarana dan prasarana sehingga akan memiliki pengaruh positif pada kesehatan dan kesejahteraan seumur hidup. Minimal, program pendidikan jasmani harus menyediakan aktivitas fisik untuk meningkatkan kesehatan. Pendidikan jasmani kesehatan dan olahraga disamping mengajarkan pengetahuan dan keterampilan yang dapat menumbuhkan komitmen jangka panjang untuk aktivitas fisik sebagai bagian dari gaya hidup sehat yang akan membantu anakanak mencegah berbagai kondisi, termasuk kolesterol abnormal, tinggi tekanan darah, hiperglikemia, obesitas, dan akhirnya penyakit jantung serta sejumlah penyakit tidak menular lainnya dan masalah kesehatan mental. Berdasarkan permasalahan di atas maka makalah ini mencoba untuk membahas terkait dengan physical education for lifelong fitness: strategi peningkatan aktivitas fisik siswa Sekolah Dasar. 


\section{PEMBAHASAN \\ PHYSICAL EDUCATION}

\section{Hakikat Physical Education}

Physical Education (PE) adalah pendidikan melalui dan tentang aktivitas fisik atau dalam bahasa Indonesia sering dikenal dengan istilah pendidikan jasmani. PE dalam bahasa aslinya dikenal dengan istilah Physical education is education of and through movement. Definisi PE tersebut, terdapat tiga kata kunci yaitu 1) pendidikan (education), yaitu kompetensi yang akan dicapai oleh siswa, 2) melalui dan tentang (through and of), menggambarkan keeratan hubungan yang dinyatakan dengan hubungan langsung dan tidak langsung (direct dan indirect), 3) gerak (movement) yaitu kajian sebagaimana tertera dalam kurikulum pendidikan jasmani (Lardika, 2014).

Pendidikan Jasmani merupakan kegiatan jasmani yang diselenggarakan sebagai media bagi kegiatan pendidikan di sekolah. Pendidikan adalah sebuah proses kegiatan dengan tujuan untuk mengembangkan sikap dan kemampuan yang meliputi aspek mental, intelektual dan bahkan spiritual. Pendidikan jasmani adalah sebuah kegiatan dalam bentuk aktiivtas jasmani dengan tujuan pendekatan ke aspek sejahtera Rohani. (Bangun, 2016).

Pendidikan jasmani adalah sebuah kegiatan untuk mengembangkan kesejahteraan total setiap orang. Karakteristik tersebut tidak terdapat pada mata pelajaran lain. Pada pendidikan jasmani merupakan hasil kependidikan dari pengalaman belajar fisikal tidak terbatas hanya pada perkembangan tubuh saja. Konteks melalui aktivitas jasmani yang dimaksud adalah konteks yang utuh menyangkut semua dimensi tentang manusia, seperti halnya hubungan tubuh dan pikiran (Abduljabar, 2011).

2. Tujuan Pendidikan Jasmani

Pendidikan jasmani pada dasarnya memiliki tujuan. Tujuan Physical Education tersebut yaitu memberikan kontribusi dan manfaat yang penting pada kesejahteraan manusia. Pendidikan jasmani bukan hanya pendidikan fisik saja, akan tetapi lebih luas lagi terkait dengan tujuan pendidikan secara menyeluruh, dan akan memberikan manfaat pada kehidupan individu (Abduljabar, 2011).

Bouchard, Calude, McPherson, Barry D., and Taylor, Albert W. (Eds). (1992). Secara umum, pendidikan jasmani berbasis sekolah bertanggung jawab untuk mengembangkan, pada semua siswa melalui nilai-nilai dasar dan menengah, kebugaran fisik, keterampilan dan pengetahuan fisik, dan sikap yang sesuai, serta memberikan saran tentang berbagai program kegiatan atletik, dan aktivitas fisik serta pada pilihan gaya hidup yang berkaitan dengan kesejahteraan fisik. Konsep utama pendidikan jasmani sekolah adalah untuk berkontribusi pada kesejahteraan optimal dan perkembangan fisik setiap individu. tujuan yang lebih spesifik termasuk perubahan perkembangan di bidang: Peningkatan keterampilan, kebugaran fisik, kontrol sosial dan emosional, kesadaran waktu luang. Lebih lanjut Bouchard, Calude, McPherson, Barry D., and Taylor, Albert W. (Eds). (1992), menyatakan bahwa pendidikan jasmani lebih memfokuskan pada: 1) Pengembangan keterampilan (Memperoleh keterampilan fisik normatif budaya, konsep pembelajaran perolehan keterampilan, mengontrol emosi dalam lingkungan aktivitas fisik, recoqnizing kemampuan pribadi dan kelemahan, dan mengetahui cara belajar dan mengontrol kinerja yang tinggi). 2) Pengembangan kebugaran (Memahami komponen utama kebugaran fisik (termasuk kekuatan dan daya tahan otot, daya aerobik dan anaerobik, fleksibilitas, dll) dan bagaimana mereka berkembang, menghargai prinsip kebugaran dasar, termasuk detak jantung, prinsip kelebihan beban, latihan interval), dan mengetahui cara untuk memantau dan meningkatkan kebugaran fisik), 3. 
Perkembangan sosial dan emosional (Mengembangkan konsep permainan yang adil dan sportif, Memahami kegiatan kompetitif dan kooperatif dan mengetahui perbedaan, Menghargai kemampuan fisik orang lain dan berinteraksi dengan orang yang memiliki kemampuan berbeda, mengembangkan dan memelihara konsep diri fisik seseorang, mengendalikan agresi dalam situasi kompetitif, Mampu untuk mengatasi menang dan kalah dalam situasi olahraga). 4. Memberikan kenyamanan (Menghargai minat, keterampilan, dan tingkat kebugaran seseorang, menjadi terbiasa dengan kegiatan fisik yang tersedia di masyarakat, memahami tuntutan berbagai tugas dan lingkungan kinerja, mampu dengan bijak menggunakan program aktivitas fisik berbasis komunitas untuk memenuhi kebutuhannya sendiri, memilih dengan cerdas dari menu aktivitas fisik.

(Bouchard, C., Barry, D., McPherson, D., \& Taylor, 1992) lebih lanjut pembagian waktu yang menunjukkan selama ini sekolah dasar awal penekanan dari program pendidikan jasmani terutama instruksional, dengan fokus yang kuat pada pengembangan keterampilan, pengenalan positif untuk aktivitas fisik, dan jauh lebih rendah pengantar untuk kegiatan kebugaran. Hal tersebut dapat dilihat pada gambar di bawah ini.

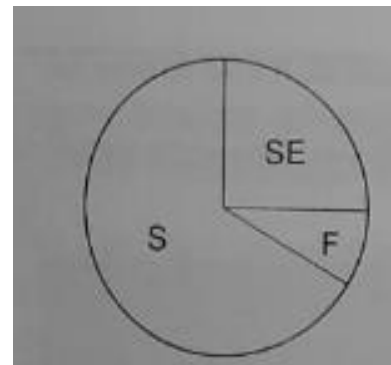

Early elementary

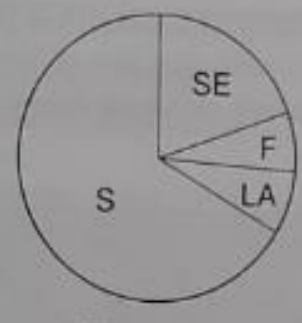

Elementary

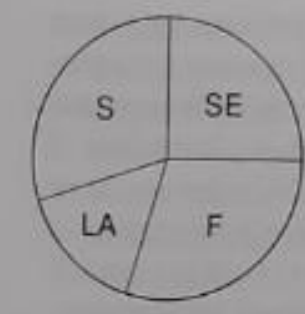

Junior high

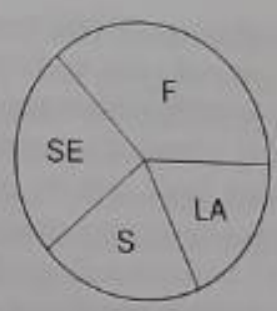

High school

Gambar 1. Pembagian waktu program pendidikan jasmani di Eropa

Keterangan: $S=$ Skill development; $S E=$ Social emotional development; $F=$ fitness development; $L A=$ Leisure awareness

Berkaitan dengan program pendidikan jasmani di sekolah, yang pada dasarnya betujuan untuk kelangsungan hidup sepanjang hayat. Aktivitas fisik memiliki efek positif tidak hanya pada kesehatan individu tetapi juga pada masyarakat secara keseluruhan karena populasi yang aktif secara fisik mampu menjadi lebih produktif. Orang yang aktif secara fisik memiliki sikap yang lebih sehat, yang memungkinkan untuk menangani masalah yang lebih besar yang terkait dengan pekerjaan atau rumah dengan cara yang lebih positif dan reflektif (Ayers \& Sariscsany, 2011).

Physical education atau biasa disebut pendidikan jasmani, memiliki tujuan yang penting. Tujuan pendidikan jasmani untuk mengembangkan kemampuan semua siswa melalui nilai-nilai dasar dan menengah, kebugaran fisik, keterampilan dan pengetahuan fisik, dan sikap yang sesuai, serta memberikan saran tentang berbagai program kegiatan atletik, dan aktivitas fisik serta pada pilihan gaya hidup yang berkaitan dengan kesejahteraan fisik

\section{AKTIFITAS FISIK}

1. Hakikat Aktifitas fisik

Aktifitas fisik menurut (Assembly, 2018; (Dasso, 2019) menyatakan bahwa aktifitas fisik adalah tiap gerak tubuh yang dihasilkan oleh otot-otot rangka yang membutuhkan pengeluaran energi, termasuk aktivitas yang dilakukan saat bekerja, bermain, melakukan pekerjaan rumah tangga, travelling, dan terlibat dalam kegiatan rekreasi. 
Definisi lain dari aktivitas fisik adalah setiap gerakan tubuh yang dihasilkan oleh otot rangka yang menghasilkan pengeluaran energi. Aktivitas fisik selain sebagai salah satu upaya dalam pencegahan kelebihan berat badan, partisipasi dalam tingkat aktivitas fisik yang memadai juga penting untuk perkembangan motorik, sosial dan kognitif anak (Cardon et al., 2014). Direkomendasikan untuk anak-anak uais 5-17 tahun untuk terlibat dalam setidaknya 60 menit / hari dalam aktivitas fisik intensitas sedang hingga kuat (moderate vigorous physical activities) (Booth et al., 2015; Moreno-Franco et al., 2020; Okely \& Janssen, 2015). Aktivitas fisik adalah apa saja gerakan tubuh yang dihasilkan dari otot rangka kontraksi yang meningkatkan pengeluaran energi di atas tingkat basal dan membakar kalori; terdiri aktivitas yang tak terhindarkan (seperti berjalan ke tempat kerja) atau ke sekolah) dan aktivitas sukarela (seperti olahraga dan rekreasi); bervariasi dalam intensitas, frekuensi, dan durasi dan meningkatkan kesehatan (Andriyani, 2014). Pendapat beberapa ahli di atas dapat disimpulkan bahwa aktifitas fisik adalah gerak yang disebabkan oleh kontaksi otot sehingga terjadi pengeluaran energi.

2. Manfaat Aktifitas fisik

Manfaat aktivitas menurut (Anshel, 2014) Bukti ilmiah yang luas menunjukkan bahwa aktivitas fisik secara teratur meningkatkan pertumbuhan dan perkembangan di masa muda dan memiliki banyak manfaat untuk kesehatan fisik, mental, dan kognitif. Pendidikan jasmani yang berkualitas, di mana siswa memiliki kesempatan untuk mempelajari konten yang bermakna dengan instruksi dan penilaian yang sesuai, merupakan strategi yang direkomendasikan berdasarkan bukti untuk meningkatkan aktivitas fisik.. Manfaat secara psikologis antara lain menurunkan stress, menurunkan kecemasan, mempengaruhi mood lebih baik, meningkatkan harga diri, peningkatan fungsi kognitif, mencegah depresi. Sedangkan manfaat secara fisiologi antara lain memberikan manfaat secara kardiorespirasi, memberikan manfaat pada kekuatan (pencegahan osteoporosis, mobilitas yang lebih besar,, mencegah terhadap cedera dan nyeri, stabilitas fisik), meningkatkan fleksibilitas.

Manfaat lain dari aktivitas fisik menurut Pedoman Pencegahan Dan Penanggulangan Kegemukan Dan Obesitas pada Anak Sekolah. Manfaat tersebut, antara lain Aktivitas fisik pada anak bermanfaat untuk : menjaga kesehatan, meningkatkan kebugaran jasmani, menjaga postur tubuh yang baik, meningkatkan keseimbangan tubuh, menjaga berat badan ideal, menjaga agar otot dan tulang yang kuat, meningkatan rasa percaya diri, menurunkan stress (Bornstein et al., 2019; Bouchard, Claude., Katzmarzyk, 2010; Dobbins et al., 2009; Moreno-Franco et al., 2020; Myers, J., Herbert, W. G., \& Humphrey et al., 2010; Wiersma, 2009)

Aktivitas fisik memiliki banyak manfaat untuk kesehatan tubuh seseorang. Manfaat aktivtas fisik dari beberapa pendapat di atas, antara lain pemeliharaan kesehatan, meningkatkan kebugaran jasmani, meninkatkan percaya diri, menurunkan stress dan menurunkan resiko penyakit tidak menular.

\section{STRATEGI PENINGKATAN AKTIVITAS FISIK SISWA SEKOLAH DASAR}

Rekomendasi aktivitas fisik juga mencakup aspek yang berhubungan dengan kesehatan menekankan juga aktivitas fisik dengan intensitas sedang penyebutan mengumpulkan aktivitas fisik dari yang lebih pendek ( $\geq 10$ menit). Rekomendasi ini menyimpulkan bahwa orang dewasa harus mengakumulasi 30 menit atau lebih pada sebagian besar hari dalam seminggu. Selain itu, kekuatan otot disebutkan untuk pertama kalinya dalam rekomendasi meskipun tidak ada rekomendasi khusus kemudian dinyatakan. Sejak tahun-tahun awal rekomendasi pertama, mengumpulkan hasil studi telah mengubah konten dan penekanan dari rekomendasi (Kay et al., 2014; Vaara et al., 2019). 
Pedoman aktivitas fisik untuk orang Amerika, rekomendasi global tentang aktivitas fisik WHO menyatakan bahwa jumlah aktivitas fisik minimum yang direkomendasikan untuk orang dewasa adalah aktivitas aerobik baik 2 jam 30 menit per minggu dengan intensitas sedang atau 1 jam dan 15 menit dengan intensitas kuat, yang dapat diakumulasikan dari 10 menit pertandingan aktivitas, Selain itu, kekuatan otot dan daya tahan otot harus dilakukan dua kali seminggu (Global Action Plan On Physical Activity 2018-2030, 2018; OMS, 2015; WHO, 2011, 2020; World Health Organization, 2010b, 2017c; Vaara et al., 2019).

Aktivitas fisik berhubungan dengan kebugaran jasmani seseoarang. Seseoarang yang rutin melakukan aktivitas fisik cenderung memiliki kebugaran jasmani yang baik. Selain itu seseorang yang melakukan aktifitas fisik akan memiliki berbagai manfaat. Manfaat aktivitas fisik pada masa anak-anak antara lain Aktivitas fisik (PA) bermanfaat untuk pencegahan penyakit dan dikaitkan dengan pengurangan risiko sejumlah besar penyakit dan kondisi, termasuk penyakit kardiovaskular, diabetes tipe 2, dan kanker payudara dan usus besar, pengaturan berat badan sehingga efektif intervensi aktivitas fisik di pengobatan dan pencegahan obesitas pediatrik. Selain itu bermanfaat secara fisiologis dan psikologis, serta dapat meningkatkan intelegensi siswa (Brazendale et al., 2021; Mena et al., 2019; Park \& Kim, 2008; Salmon et al., 2007; Wu et al., 2017).

Kunci pokok dalam pelaksanaan aktiivtas fisik untuk usia 6-17 tahun antara lain: 1) Penting untuk memberikan kesempatan dan dorongan kepada remaja untuk berperan serta dalam kegiatan fisik yang sesuai dengan usianya, yang menyenangkan, dan yang menawarkan variasi. 2) Anak-anak dan remaja usia 6 hingga 17 tahun harus melakukan 60 menit ( $1 \mathrm{jam}$ ) atau lebih aktivitas fisik sedang hingga kuat setiap hari. 3) Aerobik: Sebagian besar 60 menit atau lebih per hari harus dalam intensitas sedang atau kuat aktivitas fisik aerobik dan harus mencakup aktivitas fisik dengan intensitas tinggi setidaknya 3 hari seminggu. 4) Penguatan otot: Sebagai bagian dari aktivitas fisik harian selama 60 menit atau lebih, anak-anak dan remaja harus menyertakan aktivitas fisik penguatan otot setidaknya 3 hari seminggu. 5) Penguatan tulang: Sebagai bagian dari aktivitas fisik harian selama 60 menit atau lebih, anak-anak dan remaja harus menyertakan aktivitas fisik penguatan tulang setidaknya 3 hari seminggu (Early et al., 2013).

Hubungan antara aktivitas fisik, kebugaran yang berhubungan dengan kesehatan, dan kesehatan kompleks dan juga dipengaruhi oleh Lingkungan fisik dan sosial tempat anak menghabiskan sebagian besar waktu siswa. Penelitian telah menemukan beberapa berkorelasi dengan kebugaran fisik remaja di sekolah termasuk partisipasi pendidikan jasmani wajib, istirahat aktivitas fisik di kelas, demografi guru dan pelatihan, lamanya istirahat, peralatan dan fasilitas aktivitas fisik sekolah dan akses di luar jam sekolah, penetapan kebijakan kesehatan sekolah, kebijakan transportasi aktif, dan berlatih tes kebugaran sebelum administrasi tes (Disease Cancer Action Control \& Network, 2015). hubungan tersebut digambarkan pada gambar 2. 


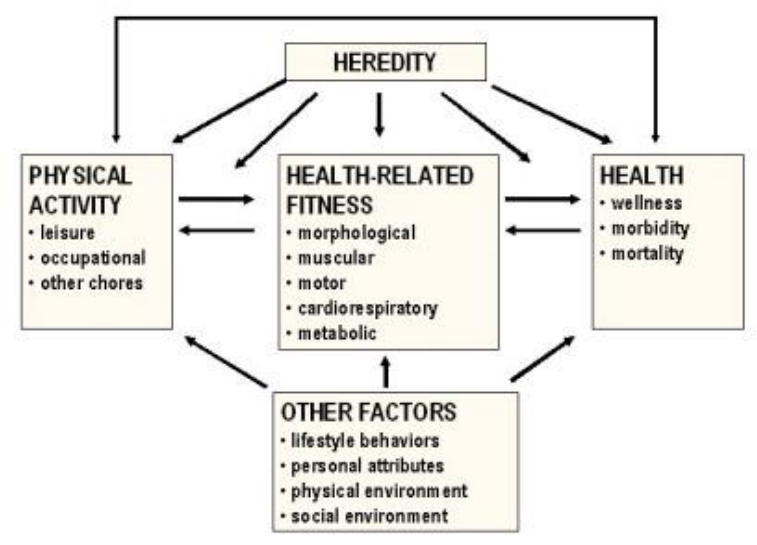

Gambar 5. Hubungan antara aktivitas fisik dengan komponen lainnya (Disease Cancer Action Control \& Network, 2015)

Berdasarkan hubungan antara aktivitas fisik, yang salah satunya menggambarkan adanya hubungan antara aktifitas fisik dengan health-related fitness, yang pada umumnya di beberapa negara secara rutin dilaksanakan tes dan pengukuran terkait dengan kebugaran jasmani siswa.

American Heart Association, American Cancer Society Cancer Action Network, dan American Diabetes Association mengharapkan pendidikan jasmani di sekolah dapat dilaksanakan secara lebih efektif dan efektif. Secara optimal, pendidikan jasmani dapat melibatkan siswa dalam mempromosikan kesehatan melalui aktivitas fisik untuk setidaknya setengah dari waktu kelas dan mengajari siswa terkait dengan pengetahuan dan keterampilan yang diperlukan untuk aktivitas fisik seumur hidup sehingga siswa dapat mejadi bugar atau PE for lifelong fitness. Aktivitas fisik di sekolah dapat dilakukan selama pembelajaran pendidikan jasmani, diluar jam pembelajaran jasmani, jam istirahat, ekstrakurikuler, dan saat siswa bermain di rumah.

Aktivitas fisik dapat dimulai dengan melaksanakan aktivitas fisik 60 menit per hari, dengan durasi 30 menit dapat dilaksanakan saat di sekolah yaitu saat jam pembelajaran pendidikan jasmani, saat istirahat sekolah, waktu kegiatan ekstrakurikuler. Kurangnya 30 menit dapat dilaksanakan di rumah dengan didampingi orang tua masingmasing, sehingga semua masyarakat dapat melaksanakan aktivitas fisik.

Sekolah melalui pendidikan jasmani yang efektif dan memberikan kesempatan lain bagi siswa untuk aktif secara fisik selama hari sekolah. Siswa dinilai untuk memperoleh pengetahuan dalam pendidikan jasmani dan status kebugaran fisik dan peningkatan dari waktu ke waktu. Selain itu, sekolah harus melaporkan hasil ini ke kabupaten dan lembaga negara. Pengembangan model aktifitas fisik perlu dilakukan dan disesuaikan dengan kebutuhan untuk pengembangan rekomendasi global yang membahas hubungan antara frekuensi, durasi, intensitas, jenis, dan jumlah total aktivitas fisik yang diperlukan untuk pencegahan NCDs. Fokus Rekomendasi Global tentang Aktivitas Fisik untuk Kesehatan adalah pencegahan primer NCD melalui aktivitas fisik di tingkat populasi, dan target audiens utama untuk Rekomendasi ini adalah pembuat kebijakan di tingkat nasional.

\section{KESIMPULAN}

Physical education for lifelong fitness .memberikan landasan filosofis yang jelas untuk program terbaik fisik dan menyajikan kerangka kerja untuk menerapkan kurikulum pendidikan jasmani terkait kesehatan untuk mempromosikan kebugaran sepanjang hayat. Aktivitas fisik secara teratur adalah salah satu faktor yang dapat 
dijadikan sebagai upaya pencegahan dan pengobatan NCDs, yaitu penyakit jantung, stroke, diabetes dan kanker payudara dan usus besar. Tujuan pendidikan jasmani adalah untuk mengembangkan siswa secara jasmani yang sehingga memiliki pengetahuan, keterampilan, dan percaya diri untuk senantiasa sehat sepumur hidup. Strategi yang dikembangkan dalam mempromosikan aktivitas fisik, harus sinergi dengan berbagai pihak antara lain, siswa, guru, orang tua dan pemangku kepentingan, sehingga usaha dalam memasyarakatkan aktivitas fisik ini dapat berjalan baik, sesuai dengan tujuannnya.

\section{DAFTAR PUSTAKA}

Abduljabar, B. (2011). Pengertian pendidikan jasmani. Ilmu Pendidikan, 1991, 36. http://file.upi.edu/Direktori/FPOK/JUR._PEND._OLAHRAGA/196509091991021 -BAMBANG_ABDULJABAR/Pengertian_Penjas.pdf

Andriyani, F. D. (2014). Physical activity Guidelines for Children. Jurnal Pendidikan Jasmani Indonesia.

Anshel, M. (2014). Applied Health Fitness Psychology. Human Kinetics.

Assembly, S. W. H. (2018). Resumo - Global action plan on physical activity 2018-2030 - more active people for a more healthier world. In Who.

Ayers, S. F., \& Sariscsany, M. J. (2011). Physical Education for Lifelong Fitness.

Bangun, S. Y. (2016). Peran Pendidikan Jasmani Dan Olahraga Pada Lembaga Pendidikandi Indonesia. Publikasi Pendidikan, 6(3). https://doi.org/10.26858/publikan.v6i3.2270

Booth, V. M., Rowlands, A. V., \& Dollman, J. (2015). Physical activity temporal trends among children and adolescents. Journal of Science and Medicine in Sport, 18(4), 418-425. https://doi.org/10.1016/j.jsams.2014.06.002

Bornstein, D., Eyler, A., Maddock, J., \& Moore, J. (2019). Physical Activity and Public Health Practice. CRC PRESS.

Bouchard, C., Barry, D., McPherson, D., \& Taylor, A. (1992). Physical Activity Sciences. Human Kinetics.

Bouchard, Claude., Katzmarzyk, P. T. (2010). Physical activity and obesity. In Human kinetic. Human Kinetics.

Brazendale, K., Beets, M. W., Armstrong, B., Weaver, R. G., Hunt, E. T., Pate, R. R., Brusseau, T. A., Bohnert, A. M., Olds, T., Tassitano, R. M., Tenorio, M. C. M., Garcia, J., Andersen, L. B., Davey, R., Hallal, P. C., Jago, R., Kolle, E., Kriemler, S., Kristensen, P. L., ... Sardinha, L. B. (2021). Children 's moderate-to-vigorous physical activity on weekdays versus weekend days : a multi-country analysis. 113.

Cardon, G., De Craemer, M., De Bourdeaudhuij, I., \& Verloigne, M. (2014). More physical activity and less sitting in children: Why and how? Science \& Sports, 29, S3-S5. https://doi.org/10.1016/j.scispo.2014.08.002

Dasso, N. A. (2019). How is exercise different from physical activity? A concept analysis. Nursing Forum, 54(1), 45-52. https://doi.org/10.1111/nuf.12296

Disease Cancer Action Control, \& Network. (2015). Increasing and Improving Physical Education and Physical Activity in Schools : Benefits for Children's Health and Educational Outcomes. American Heart Association, April.

Dobbins, M., DeCorby, K., Robeson, P., Husson, H., \& Tirilis, D. (2009). School-based physical activity programs for promoting physical activity and fitness in children and adolescents aged 6-18. In Cochrane Database of Systematic Reviews (Issue 1, pp. 1-228). https://doi.org/10.1002/14651858.CD007651

Dunstan, D. W., Howard, B., Healy, G. N., \& Owen, N. (2012). Too much sitting - A health hazard. Diabetes Research and Clinical Practice, 97(3), 368-376. https://doi.org/10.1016/j.diabres.2012.05.020 
Early, W., Obesity, C., Initiative, P., Start, H., Taken, S., Activity, P., \& Program, O. (2013). Physical Activity Guidelines for Americans. 202, 56-63.

Global Action Plan On Physical Activity 2018-2030, W. (2018). Global action plan on physical activity 2018-2030: more active people for a healthier world. Geneva: World Health Organization; 2018. Licence: CC BY-NC-SA 3.0 IG. In Who.

González, K., Fuentes, J., \& Márquez, J. L. (2017). Physical Inactivity , Sedentary Behavior and Chronic Diseases. Korean Journal of Family Medicine, 111-115.

Kay, M. C., Carroll, D. D., Carlson, S. A., \& Fulton, J. E. (2014). Awareness and knowledge of the 2008 physical activity guidelines for americans. In Journal of Physical Activity and Health. https://doi.org/10.1123/jpah.2012-0171

Kemenkes RI. (2018). Hasil Utama Riskesdas 2018.

Lardika, R. A. (2014). Pengaruh model pembelajaran inquiry dalam pendidikan jasmani terhadap tingkat adversity quotient (aq) siswa. 13-47.

Medina, C., Jáuregui, A., Hernández, C., Shamah, T., \& Barquera, S. (2021). Physical inactivity and sitting time prevalence and trends in Mexican adults. Results from three national surveys. PloS One, 16(7), e0253137. https://doi.org/10.1371/journal.pone.0253137

Mena, G. P., Mielke, G. I., \& Brown, W. J. (2019). The effect of physical activity on reproductive health outcomes in young women: a systematic review and metaanalysis. 1-23. https://doi.org/10.1093/humupd/dmz013

Moreno-Franco, B., Penalvo, J. L., Andres-Esteban, E. M., Malo, S., Lallana, M. J., Casasnovas, J. A., Leon-Latre, M., Pearson, N., Braithwaite, R., Biddle, S. J. H. H., Education, P., Before, P. A., Involvement, S., Involvement, C., Plowman, S. A., Centers for Disease Control and Prevention, (CDC), Guide, R., Högman, J., Augustsson, C., ... Donen, R. M. (2020). Global recommendations on physical activity for health. BMC Public Health, 4(1), 1-10. https://doi.org/10.1016/j.pmrj.2012.09.585

Myers, J., Herbert, W. G., \& Humphrey, R. H. (Eds. ., Smith, A. L., Biddle, S. J. H., That, A., Learning, P., Bouchard, Claude., Katzmarzyk, P. T., Nies, M. A., Mcewen, M., Bouchard, C., Blair, S. N., Haskell, W. L., Humphrey, N. P., Dobbins, M., Husson, H., Decorby, K., Larocca, R. L., Draper, N., Stratton, G., Modeling, E., ... Coordinator, P. (2010). Ergonomics in Sport and Physical Activity: enhancing performance and improving safety. In A. Myers,J., Nieman,D., Frey,G., Pitetti,K., Herbert,W., Kaleth (Ed.), Choice Reviews Online (1st ed., Vol. 35, Issue 1). Human Kinetics. https://doi.org/10.7256/2454-0625.2020.1.30247

Okely, A. D., \& Janssen, X. (2015). Early physical activity and sedentary behaviours. Early Years Nutrition and Healthy Weight, 46-58. https://doi.org/10.1002/9781119023258.ch5

Park, H., \& Kim, N. (2008). Predicting factors of physical activity in adolescents: A systematic review. Asian Nursing Research, 2(2), 113-128. https://doi.org/10.1016/S1976-1317(08)60035-3

Salmon, J., Booth, M. L., Phongsavan, P., Murphy, N., \& Timperio, A. (2007). Promoting physical activity participation among children and adolescents. Epidemiologic Reviews, 29(1), 144-159. https://doi.org/10.1093/epirev/mxm010

Stamatakis, E., Gale, J., Bauman, A., Ekelund, U., Hamer, M., \& Ding, D. (2019). Sitting Time, Physical Activity, and Risk of Mortality in Adults. 73(16). https://doi.org/10.1016/j.jacc.2019.02.031

Vaara, J. P., Vasankari, T., Koski, H. J., \& Kyröläinen, H. (2019). Awareness and Knowledge of Physical Activity Recommendations in Young Adult Men. Frontiers in Public Health. https://doi.org/10.3389/fpubh.2019.00310

WHO. (2018). Global action plan on physical activity 2018-2030: more active people for a healthier world. Geneva: World Health Organization; 2018. Licence: CC BY- 
NC-SA 3.0 IG. In Who.

WHO. (2020). WHO Guidelines on physical activity and sedentary behaviour. In World Health Organization.

Wiersma, L. (2009). Youth Physical Activity and Sedentary Behavior: Challenges and $\begin{array}{llll}\text { Solutions. The Sport Psychologist, 23(4), 562-563. } & \text { The }\end{array}$ https://doi.org/10.1123/tsp.23.4.562

World Health Organization. (2010). World Health Organization: Global Recommendations on PhyDalgleish, Tim Williams, J. Mark G.. Golden, AnnMarie J. Perkins, Nicola Barrett, Lisa Feldman Barnard, Phillip J.sical Activity for Health: WHO 2010. Journal of Experimental Psychology: General, 136(1), 23-42. https://www.who.int/dietphysicalactivity/global-PA-recs-2010.pdf

World Health Organization. (2011). Physical-Activity-Recommendations-5-17 Years. Who, 1(1), 1-2.

World Health Organization. (2015). Physical activity strategy for the WHO European Region 2016-2025. Organización Mundial de La Salud, 1.

World Health Organization. (2016). Noncommunicable Disease. In Heart of Africa: Clinical Profile of an Evolving Burden of Heart Disease in Africa. https://doi.org/10.1002/9781119097136.part5

World Health Organization. (2017a). Physical activity for health: More active people for a healthier world (draft global action plan on PA 2018-2030). Who.

World Health Organization. (2017b). WHO 10 facts on physical activity. WHO.

World Health Organization. (2018a). ACTIVE - A technical package for increasing physical activity. World Health Organization 2018.

World Health Organization. (2018b). Let's be active, the global action plan on physical activity 2018 - 2030. World Health Organization.

Wu, X. Y., Han, L. H., Zhang, J. H., Luo, S., Hu, J. W., \& Sun, K. (2017). The influence of physical activity, sedentary behavior on health-related quality of life among the general population of children and adolescents : A systematic review. 1-29. 